\title{
Hepatitis $C$ virus in autoimmune liver disease in the UK: aetiological agent or artefact?
}

\author{
B P Rowan, A Smith, D Gleeson, L P Hunt, T W Warnes
}

\begin{abstract}
Hepatitis C virus antibody titres (anti-HCV) were measured in serum from 122 patients with autoimmune liver disease (96 with primary biliary cirrhosis and 26 with autoimmune chronic active hepatitis using three generations of enzyme immunoassay (EIA): first generation - Ortho, EIA1; second generation Abbott, EIA2; and third generation - Murex, EIA3. Anti-HCV was below the positive cut-off level in all 26 autoimmune chronic active hepatitis patients for all tests, while seropositivity values in primary biliary cirrhosis were $31 \%$ (EIA1), 14\% (EIA2), and 0\% (EIA3). In primary biliary cirrhosis, anti-HCV values as measured by all three tests correlated positively with serum IgG concentrations, serum storage time, and a number of other indices of hepatic dysfunction. Multiple regression analysis showed that anti-HCV values were independently affected by both serum IgG and the length of storage time, although the magnitude of the effects varied between tests. When all three multiple regression models were applied to an extreme clinical example, however, EIA3 was least likely to give a false-positive result. The difference in test performance was emphasised further by examination of anti-HCV values in nine primary biliary cirrhosis patients (confirmed negative by recombinant immunoblot assay 2) in whom serial samples were tested (seven to 14 per patient, stored for one to 138 months). Apparent anti-HCV values (EIA1 and EIA2) increased with increasing serum storage time, but were unchanged when measured by EIA3. A similar pattern was evident in a limited study of five autoimmune chronic active hepatitis patients. Thus, in the largest study reported to date, there is no evidence of an important aetiological role for $\mathrm{HCV}$ in autoimmune chronic active hepatitis or primary biliary cirrhosis in the UK. The third generation of anti-HCV EIAs is the most reliable screening test, will avoid costly and unnecessary confirmatory testing, and may partly clarify the existing geographical heterogeneity in antiHCV seroprevalence. An accurate diagnosis of past HCV infection is an important determinant in the choice of treatment in autoimmune chronic active hepatitis. As the second generation EIA is in widespread use and confirmatory testing is not always available, the effect of serum storage in addition to hyperglobulinaemia should be considered in the interpretation of positive results in autoimmune and in other types of chronic liver disease.
\end{abstract}

(Gut 1994; 35: 542-546)
The development of an enzyme immunoassay (EIA) in 1989 for antibodies to hepatitis C viral antigens (anti-HCV) in serum ${ }^{12}$ and the subsequent development of a recombinant immunoblot assay (RIBA) ${ }^{3}$ stimulated much investigation into the possible pathogenetic role of hepatitis $\mathrm{C}$ infection in chronic liver disease.

Published studies of type 1 autoimmune chronic active hepatitis (CAH) showed a wide variation in seroprevalence of anti-HCV as measured by first generation screening tests, unconfirmed by first generation RIBA (RIBA-1): $6 \%$ (USA), ${ }^{4} 14 \%$ and $40 \%$ (UK), ${ }^{56}$ $33 \cdot 35 \%$ (Scandinavia), ${ }^{78} 44 \%$ (Spain), $90 \%$ (Japan), ${ }^{10}$ and $57 \%$ (France). ${ }^{11}$ One Italian group which performed RIBA-1 tests reported that $57 \%$ of type 1 patients were positive. ${ }^{12}$

In type 2 autoimmune $\mathrm{CAH}$, two Italian reports of RIBA-1 confirmed seropositive patients showed prevalence figures of 73$85 \%{ }^{12}{ }^{13}$ In the study of Todros $e t a l^{13}$ most of the patients who were given interferon experienced rapid clinical remission of their disease.

Reported seropositivity in primary biliary cirrhosis (PBC) has ranged from $0 \%$ (UK and France) ${ }^{5611}$ to $12 \%$ (Italy), ${ }^{14} 13 \%$ (Japan), ${ }^{10} 25 \%$ (Norway), ${ }^{8}$ and $27 \%$ and $35 \%$ (Italy). ${ }^{15} 16$ One French group who reported $33 \%$ seroprevalence at initial screening was able to confirm only $1 \%$ by RIBA-1. ${ }^{17}$

As a result of these initial screening studies, the unexpectedly high prevalence in some countries suggested that $\mathrm{HCV}$ contributed to the pathogenesis of both PBC and autoimmune $\mathrm{CAH}$; this has important therapeutic implications since a number of groups suggest some benefit from interferon treatment in chronic hepatitis C. ${ }^{13} 18$

The specificity of the first generation assay that uses recombinant antigen c100-3 derived from non-structural regions 3 and 4 of the $\mathrm{HCV}$ genome was questioned, however, by McFarlane et al, who reported falsely high anti-HCV values in autoimmune $\mathrm{CAH}$ patients with hyperglobulinaemia. ${ }^{6}$ Other groups reported interference in the assay from superoxide dismutase antibodies, ${ }^{19}$ rheumatoid factors, ${ }^{20}$ and paraproteinaemia. ${ }^{21}$ The possibility that sample storage might cause false-positive results has been raised $^{8172223}$ but has not been systematically investigated in either $\mathrm{CAH}$ or $\mathrm{PBC}$, and very few authors make any comment about duration of serum storage. Since most published studies have relied on stored sera, information on the importance of prolonged storage on anti-HCV is vital. For most study centres, confirmatory immunoblot tests are expensive and routine measurement of HCV-RNA is unavailable. 
Thus, it is of utmost importance to have a reliable screening test available.

Second generation EIAs are now routinely in use, although results from first generation tests are still being reported. ${ }^{24}$ It has been claimed that the addition of new recombinant antigens derived from the core (c22-3) and non-structural regions 3 and 4 (c33c) allows detection of anti$\mathrm{HCV}$ in an additional $10-20 \%$ of patients from high risk groups ${ }^{25}$ and has decreased the length of the window period between HCV infection and seroconversion. ${ }^{26}$ It was also hoped that the introduction of second generation tests would result in increased specificity, but the few studies of autoimmune liver disease which have been reported suggest that the problem of falsepositive results persists, though the mechanism has not previously been investigated. Discrepancies in seroprevalence figures using only RIBA-2 confirmed cases show that geographical heterogeneity is still apparent (Table I). ${ }^{1425} 2728$

A third generation test, which includes for the first time an antigen derived from the NS5 region in addition to antigens from the core and NS3 region, has recently become available from Murex.

This paper reports results from the largest group of patients with autoimmune liver disease examined to date. The prevalence of anti-HCV has been determined in $122 \mathrm{UK}$ patients with $\mathrm{PBC}$ and autoimmune $\mathrm{CAH}$ using the Ortho first generation (EIA1), Abbott second generation (EIA2), and Murex third generation (EIA3) EIAs. Seropositive samples were retested in selected cases using the second generation Chiron four-antigen RIBA test (RIBA-2). ${ }^{29} \mathrm{We}$ have investigated the possible mechanism of false-positive anti-HCV tests by examining the relationship between anti-HCV values and parameters of inflammatory activity and hepatic dysfunction. In addition, we have investigated in detail the effect of prolonged serum storage on anti-HCV values in both disease groups.

\section{Patients and methods}

Ninety six patients with PBC were studied: 77 were investigated using EIAl and all 96 were tested with EIA2 and EIA3. All had raised serum alkaline phosphatase activities, positive antimitochondrial antibody titres $(>1: 100)$, and histological features diagnostic of, or compatible with, primary biliary cirrhosis. Serum samples were stored at $-20^{\circ} \mathrm{C}$, with storage time varying from less than one month to 161 months.

Sera from 26 patients with CAH were tested for anti-HCV. Testing with EIAl was performed on the day of collection $(n=22)$ or after storage for less than two weeks at $-20^{\circ} \mathrm{C}(n=4)$. Testing with EIA 2 and EIA 3 was carried out 33 months later after storage at $-20^{\circ} \mathrm{C}$. At presentation, all patients had histological features of CAH. None gave a history of drug or alcohol abuse. Serum from all patients showed normal copper oxidase activity and was negative for hepatitis B markers. In 22 patients, titres of antinuclear antibody or smooth muscle antibody, or both, exceeded 1:100 (autoimmune group).

In nine $\mathrm{PBC}$ and five autoimmune $\mathrm{CAH}$ patients, sequentially obtained serum samples were tested for anti-HCV (PBC: stored 1-138 months (EIA1); 3-135 months (EIA2 and EIA3); CAH: stored 7-112 months (EIA1); 8-136 months (EIA2 and EIA3)).

Anti-HCV was measured using three EIAs: EIA1 - Ortho Diagnostics employing cl00-3 (NS3/NS4); EIA2 - Abbott employing c200 (NS3/NS4) and c22 (core); EIA3 - Murex employing BHC28 (a fusion protein of three antigens from core, NS3 and NS5). Typical antiHCV test cut-off levels measured in our laboratory were 0.57 (Ortho), 0.33 (Abbott), and 0.65 (Murex) optical density (OD) units. Samples which were initially positive were confirmed by retesting in duplicate. Eight seropositive PBC samples (by EIAl and 2) were retested using the Chiron second generation RIBA (RIBA-2) employing four recombinant $\mathrm{HCV}$ antigens. ${ }^{12}$

Serum immunoglobulins, aspartate and alanine aminotransferases (AST, ALT), bilirubin, and albumin had been measured by routine techniques when samples were initially obtained.

Correlations between pairs of variables were assessed using Pearson correlation coefficients employing two-tailed tests of significance. A logarithmic transformation was used to obtain a Gaussian distribution of data points for all parameters with the exception of serum storage time (EIA-1) and albumin. The independent relationships between these variables and anti-HCV levels were further explored using multiple regression analysis.

\section{Results}

In the group of 77 patients with PBC tested by EIA1, anti-HCV values were positive in 24 $(31 \%)$, and correlated positively with serum storage time $(r=0.55, p<0.001)$. Anti-HCV values were positive in only two of 46 patients in whom serum had been stored for less than 18 months but were positive in 22 of 31 in whom serum had been stored for longer than 18 months ( $<<0 \cdot 001: \chi^{2}$ with Yates's correction). Of the 24 patients with raised values, $38 \%$ had OD values more than twice the cut-off value.

Of the 96 PBC patients tested by the second generation assay, anti-HCV seroprevalence was $14 \%$ and values again correlated positively with the serum storage time $(\mathrm{r}=0.71, \mathrm{p}<0.001)$. Of the 13 patients with raised anti-HCV levels, all had OD values less than twice the cut-off value.

No patients tested positive by the third generation assay. In the whole group of 96 , however, there was a positive correlation

TABLE I Hepatitis $C$ virus antibody seroprevalence in autoimmune liver disease: second generation screening test results

\begin{tabular}{lcc}
\hline & $\begin{array}{l}\text { Positivity } \\
\text { Country (disease type) }\end{array}$ & Confirmed (RIBA-2) (\%) \\
\hline Autoimmune chronic active & hepatitis: & \\
Italy (type 1) & 46 & 39 \\
USA (type 1) & 45 & 3 \\
France (type 2) & 76 & 49 (all HCV-RNA + ve) \\
Primary biliary cirrhosis: & 17 & 7 \\
Italy & 44 & 6 \\
USA & & \\
\hline
\end{tabular}

RIBA = recombinant immunoblot assay; $\mathrm{HCV}=$ hepatitis $\mathrm{C}$ virus 
TABLE II Three models derived by multiple regression analysis showing parameters which have independent effects on hepatitis $C$ virus antibody (anti-HCV), as measured by three generations of screening test. Units are in months (storage time) and g/l (IgG, IgA, albumin).

Ortho-1:

$\log _{10}$ anti-HCV $=-2 \cdot 56+0 \cdot 004$ storage time $e^{\star \star \star}+1 \cdot 58 \log _{10} I g G^{\star \star \star}$

Abbott-2:

$\log _{10}$ anti-HCV $=-1.62+0.303 \log _{10} \mathrm{IgG}^{\star \star}+0.263 \log _{10} \mathrm{IgA} \mathrm{A}^{\star \star}+0.258 \log _{10}$ storage time $\mathrm{s}^{\star \star}$ Murex-3:

$\log _{10}$ anti-HCV $=-2 \cdot 29+0 \cdot 00979$ albumin $^{\star}+0.737 \log _{10} I g G \star \star \star+0 \cdot 101 \log _{10}$ storage time ${ }^{\star}$

${ }^{\star} \mathrm{p}<0.05, \star \star \mathrm{p}<0.01,{ }^{\star \star \star} \mathrm{p}<0.001$.

TABLE III Hepatitis $C$ virus (anti-HCV) antibody values as predicted by each of the three models followed by $95 \%$ prediction intervals (in brackets), assuming the clinical conditions of a 'worst case scenario' for potential false-positive anti-HCV results: serum IgG $=30 \mathrm{~g} / \mathrm{l}$, serum $I g A=7 \mathrm{~g} / \mathrm{l}$, serum albumin $=25 \mathrm{~g} / \mathrm{l}$, and serum storage time $=60$ months or 120 months. Typical anti-HCV test cut-off levels measured in our laboratory are 0.57 (Ortho), 0.33 (Abbott), and 0.65 (Murex). Results printed in bold type represent positive anti-HCV titres

\begin{tabular}{clll}
\hline & Enzyme immunoassay & & \\
\cline { 2 - 4 } Storage time & Ortho-1 $($ OD units $)$ & Abbott-2 $($ OD units $)$ & Murex-3 (OD units $)$ \\
\hline 60 Months & $\mathbf{1 . 0 0 6}(0.433-2.342)$ & $0.324(0 \cdot 190-0.550)$ & $0 \cdot 165(0.081-0.336)$ \\
120 Months & $\mathbf{1 . 6 8 5}(0.703-4.035)$ & $0.387(0.227-0.659)$ & $0 \cdot 177(0.087-0.360)$ \\
\hline
\end{tabular}
storage time $(r=0.27, p<0.01)$.

A series of univariate analyses showed that anti-HCV as measured by all three tests correlated with serum IgG concentrations and a number of other indices of hepatic dysfunction. With multiple regression analysis, however, most of these correlations became nonsignificant. Variables which affect anti-HCV values independently are shown in Table II. Both serum IgG and storage time were independently associated with anti-HCV values as measured by all three assays, although the magnitude of the effects varied between assays. Additionally, anti-HCV, as measured by EIA2, was affected by serum IgA concentrations, and anti-HCV, as measured by EIA3, was affected by serum albumin concentrations.

Although these correlations are of statistical significance, their effect on anti-HCV values may be of little clinical relevance. To assess their
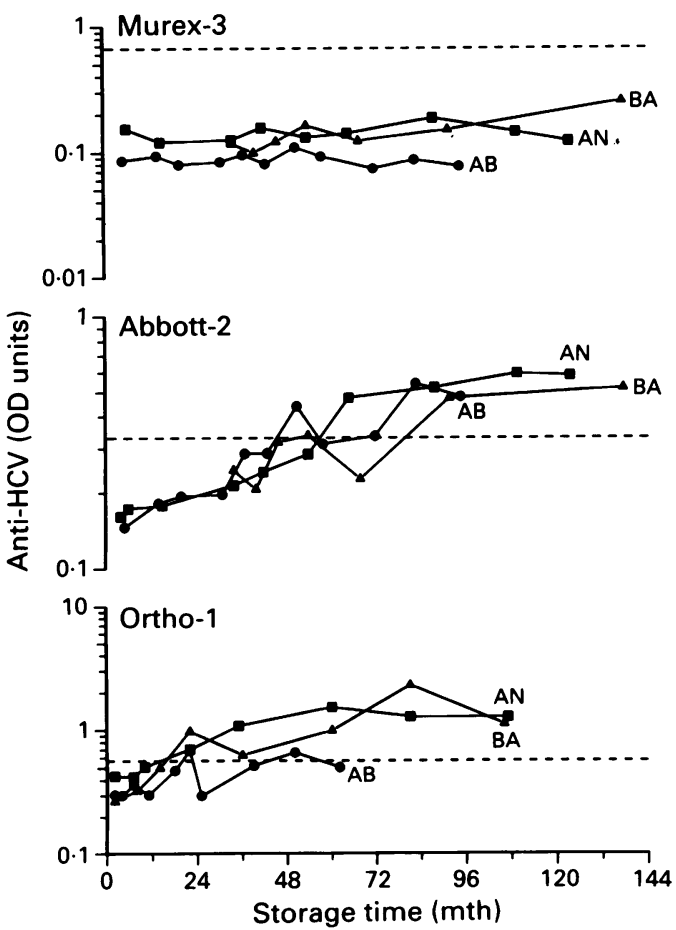

Figure 1: Hepatitis $C$ virus antibody (anti-HCV) levels in three primary biliary cirrhosis patients followed over 12 years. The dashed (Abbott), and 0.65 (Murex). $O D=$ optical density. level: 0.57 (Ortho), 0.33 practical importance a theoretical 'worst clinical case' was examined in which predictions of the anti-HCV value were made on the basis of the three multiple regression models using an IgG concentration of $30 \mathrm{~g} / \mathrm{l}, \mathrm{IgA} 7 \mathrm{~g} / \mathrm{l}$, albumin $25 \mathrm{~g} / \mathrm{l}$, and serum storage times of 60 or 120 months (Table III). This example shows clearly that use of the Murex screening test was highly unlikely to give a false-positive result even under these extreme conditions.

In order to study further the effects of the serum storage time, nine $\mathrm{PBC}$ patients were studied sequentially. Mean IgG concentrations did not change significantly over the time that they were followed (median follow up of 96 months). However, anti-HCV titres, as measured by EIAl and EIA2, rose progressively with increasing serum storage time, with $r$ values for the nine individual patients ranging from $0 \cdot 55-0.93$. Thus, anti-HCV values were consistently higher in the earliest obtained, longest stored sera. An EIA positive sample from eight of these nine patients was retested using RIBA-2 and all eight were found to be negative. When the same nine patients were studied sequentially with the third generation Murex test, results showed that anti-HCV values remained below the cut-off point and were virtually unchanged regardless of increasing storage time (Fig 1).

Fresh serum samples were tested by EIA1 in all 26 patients with $\mathrm{CAH}$. Further testing by EIA2 and EIA3 was performed after storage for 33 months. In every case, for all three tests, antiHCV values were below the positive cut-off value. Even within this normal range, however, significant positive correlations were found between anti-HCV values (EIAl and EIA3) and indices of inflammatory disease activity: serum IgG and AST (Table IV). Patient numbers were too small to perform multiple regression analysis and therefore these significant univariate associations may not be independent. The effect of storage time could not be examined in this group as the samples had all been stored for the same length of time but in five patients in whom sequential serum samples were tested, anti-HCV values (EIA1 and EIA2) rose with increasing storage time in four, but remained unchanged and were always well below the cut-off point when tested by EIA3 (Fig 2).

\section{Discussion}

There now seems to be general agreement that the hepatitis $\mathrm{C}$ virus plays some part in autoimmune CAH in Italy, and may even act as the antigenic trigger in autoimmune liver disease. Previous studies of HCV based on the use of first generation assays have reported an unexpectedly variable frequency of anti-HCV seropositivity in autoimmune liver disease, and in some results reexamined by RIBA, a high level of apparent false-positives. McFarlane et al suggested hyperglobulinaemia as the source of the artefact with non-specific binding of protein to the assay solid phase. ${ }^{6}$

It was hoped that the introduction of second generation screening tests would reduce the incidence of false-positive results, clarifying the apparent geographical heterogeneity. Second 
TABLE IV Univariate regression analysis in autoimmune chronic active hepatitis; correlations with hepatitis $C$ virus values

\begin{tabular}{|c|c|c|c|c|c|c|c|c|c|}
\hline & \multicolumn{3}{|c|}{ Ortho-1 } & \multicolumn{3}{|c|}{ Abbott-2 } & \multicolumn{3}{|c|}{ Murex-3 } \\
\hline & No & $r$ & p Value & No & $r$ & p Value & No & $r$ & p Value \\
\hline $\begin{array}{l}\text { IgG } \\
\text { AST } \\
\text { ALT }\end{array}$ & $\begin{array}{l}26 \\
26 \\
26\end{array}$ & $\begin{array}{l}0.52 \\
0.54 \\
0.34\end{array}$ & $\begin{array}{l}\mathrm{p}<0.01 \\
\mathrm{p}<0.01 \\
\text { NS }\end{array}$ & $\begin{array}{l}24 \\
25 \\
25\end{array}$ & $\begin{array}{l}0.17 \\
0.06 \\
0.04\end{array}$ & $\begin{array}{l}\text { NS } \\
\text { NS } \\
\text { NS }\end{array}$ & $\begin{array}{l}24 \\
25 \\
25\end{array}$ & $\begin{array}{l}0.85 \\
0.78 \\
0.69\end{array}$ & $\begin{array}{l}\mathrm{p}<0.001 \\
\mathrm{p}<0.001 \\
\mathrm{p}<0.001\end{array}$ \\
\hline
\end{tabular}

AST $=$ aspartate aminotransferase; ALT $=$ alamine aminotransferase.

generation testing has resulted in improved sensitivity in high risk groups but there are still discrepancies in figures reported for lower risk groups and two studies have questioned the specificity of the test particularly in autoimmune disease. ${ }^{14} 25$ No clear explanation currently exists for the divergent findings of both first and second generation tests. The clinician's dilemma hinges on whether the anti-HCV assays will help in the selection of patients for anti-viral treatment. The serious consequences of inadvertently treating patients with true autoimmune disease with interferon instead of steroids have been well documented..$^{30}$ Since confirmatory tests may not always be available there is an urgent need for screening assays which minimise the possibility of false-positive results.

In our study of autoimmune $\mathrm{CAH}$ patients, the prevalence of anti-HCV in sera, whether freshly obtained or stored frozen for 33 months, using all three generations of test, was zero. Most of our patients with $\mathrm{CAH}$ had clinically inactive disease with normal or only slightly raised serum IgG values; this probably accounts for our finding of zero positivity compared with the $40 \%$ observed by McFarlane et al, also in patients from the UK. ${ }^{6}$ Sequential anti-HCV analysis of serial samples from a small autoimmune $\mathrm{CAH}$ group, which had been stored over a longer period (up to 136 months) showed a pattern of
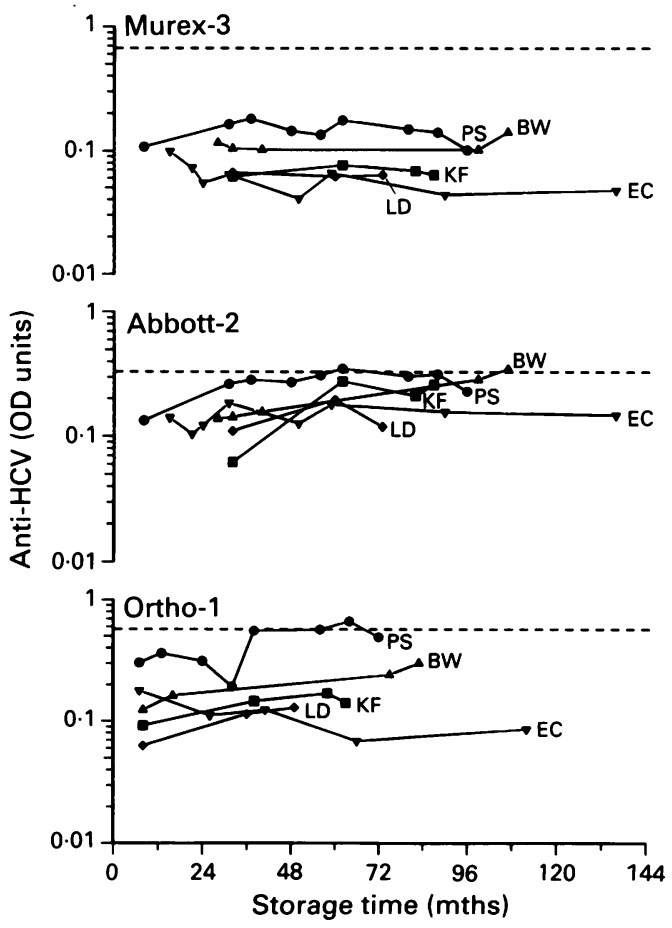

Figure 2: Hepatitis $C$ virus antibody (anti-HCV) levels in five patients with autoimmune chronic active hepatitis followed over 12 years. $O D=$ optical density. rising anti-HCV values in four out of five cases with EIA1 and EIA2; no such rise was evident, however, with EIA3.

The overall incidence of anti-HCV in our group of primary biliary cirrhosis patients decreased with each generation of screening test from $31 \%$ (EIA1), to $14 \%$ (EIA2), to $0 \%$ (EIA3). Full analysis suggests that the positive results found with EIA1 and EIA2 are 'false-positives' and arise for two reasons. In all assay systems multiple regression analysis showed positive, independent links between anti-HCV and serum IgG and also, for the first time, with serum storage time. By applying multiple regression models to a theoretical 'worst clinical case' for all three tests, we have shown that from a practical viewpoint, use of the third generation test is highly unlikely to give a false-positive result. In addition, sequential analysis of nine primary biliary cirrhosis patients, confirmed as anti-HCV negative by RIBA-2, showed that apparent anti$\mathrm{HCV}$ values (EIAl and EIA2) rose with increasing storage time and eight became positive, independent of changes in inflammatory activity or hepatic function. Sequential anti-HCV analysis of the same patients by EIA3 resulted in no change in anti-HCV values despite storage for up to 136 months.

We have witnessed an explosion of interest in $\mathrm{HCV}$ and the application of assays to establish $\mathrm{HCV}$ prevalence in chronic liver disease. Most groups have moved on to second generation screening tests, but high levels of false-positives are still apparent and geographical heterogeneity is yet to be explained. We propose that the use of stored samples in retrospective studies in addition to differences in serum IgG values may account for some of the variability in the incidence of HCV seropositivity in previous reports. We have shown that use of the Murex screening EIA eliminated the problem of false-positive results in the two forms of liver disease in the UK that are classically thought to have an autoimmune basis.

The introduction of interferon treatment for HCV positive $\mathrm{CAH}$ now makes the accurate assessment of $\mathrm{HCV}$ status in every patient with $\mathrm{CAH}$ of great importance. In the current situation where routine measurement of HCV-RNA in serum is not a likely prospect for most study centres and confirmatory immunoblot tests are expensive and may not be readily available, it is highly desirable to have available a frontline screening test that is both sensitive and specific. We propose that the third generation of EIA is the most reliable screening test to date. From the present study, the largest so far reported, we find no evidence for a significant aetiological role for $\mathrm{HCV}$ in primary biliary cirrhosis or autoimmune type $1 \mathrm{CAH}$ in the UK.

Part of this work has been published in abstract form in Gut 1991; 32: A554.

We would like to acknowledge the generous assistance of several groups: Ortho Diagnostics Ltd and Murex Diagnostics Ltd who provided us with EIA and RIBA kits used in this investigation and Dr Elizabeth Love and Mr Don Roach of Manchester Blood Transfusion Service who performed second generation screening tests on all samples.

1 Choo Q-L, Kuo G, Weiner AJ, et al. Isolation of a cDNA clone derived from a blood-borne Non-A, Non-B viral hepatitis genome. Science 1989; 244: 359-62. 
2 Kuo G, Choo Q-L, Alter HJ, et al. An assay for circulating antibodies to a major etiologic virus of human non- $A$, non- $B$ hepatitis. Science 1989; 244: 362-4.

3 Ebeling F, Naukkarinen R, Leikola J. Recombinant immunoblot assay for hepatitis $\mathrm{C}$ virus antibody as predictor of infectivity. Lancet 1990; 335: 982-3.

4 Czaja AJ, Taswell HF, Rakela J, Schimek CM. Frequency and significance of antibody to hepatitis $\mathrm{C}$ virus in severe corticosteroid-treated autoimmune chronic active hepatitis. Mayo Clin Proc 1991; 66: 572-82.

5 Jacyna MR, O'Neill K, Brown J, Drobner J, Karayiannis P, Thomas HC. Hepatitis $\mathrm{C}$ virus antibodies in subjects with and without liver disease in the United Kingdom. $Q \mathcal{F} \mathrm{Med}$ and without liver diseas 282 : 1009-12.

6 McFarlane IG, Smith HM, Johnson PJ, et al. Hepatitis C virus antibodies in chronic active hepatitis: pathogenetic factor or antibodies in chronic active hepatitis: pathoge
false-positive result? Lancet 1990; 335: 754-7.

7 Schvarcz R, Von Sydow M, Weiland O. Autoimmune chronic active hepatitis; changing reactivity for antibodies to hepatitis $\mathrm{C}$ virus after immunosuppressive treatment. Scand $\mathcal{f}$ Gastroenterol 1990; 25: 1175-80.

8 Schrumpf E, Elgjo K, Fausa O, et al. The significance of antihepatitis $\mathrm{C}$ virus antibodies measured in chronic liver disease. Scand f Gastroenterol 1990; 25: 1169-74.

9 Esteban JI, Esteban R, Viladomiu L, et al. Hepatitis C virus antibodies among risk groups in Spain. Lancet 1989; ii: $294-6$.

10 Onji M, Kikuchi T, Michitaka K, et al. Detection of hepatitis $C$ virus antibody in patients with autoimmune hepatitis and
other chronic liver disease. Gastroenterol $\mathcal{f p n} 1991$; 26: other $182-6$.

11 Deny P, Nicolas J-C, Loiseau D, Lefrere J-J. Prevalence of antibodies to hepatitis $\mathrm{C}$ in different aetiologies of cirrhosis. F Hepatol 1990; 11: 393.

12 Lenzi M, Johnson PJ, McFarlane IG, et al. Antibodies to hepatitis $C$ virus in autoimmune liver disease: evidence for geographical heterogeneity. Lancet 1991; 338: 277-80.

13 Todros L, Touscoz G, U'Urso N, et al. Hepatitis C virus-related chronic liver disease with autoantibodies to liver-kidney microsomes (LKM). I Hepatol 1991; 13: 128-31.

14 Bertolini E, Battezzati PM, Zermiani $P$, et al. Hepatitis $C$ virus testing in primary biliary cirrhosis. $\mathcal{f}$ Hepatol 1992; 15: 207-10.

15 Chiaramonte M, Floreani A, Giacomini A, et al. Anti-HCV in primary biliary cirrhosis. Gut 1990; 31: A626.
16 Fusconi M, Lenzi M, Ballardini G, et al. Anti-HCV testing in autoimmune hepatitis and primary biliary cirrhosis. Lancet 1990; 336: 823 .

17 Housset C, Hirschauer C, Degos F. False-positive anti-HCV in biliary cirrhosis. Ann Intern Med 1991; 114: 252.

18 Magrin S, Craxi A, Fiorentino G, et al. Is autoimmune chronic active hepatitis an HCV-related disease? f Hepatol 1991; 13: $56-60$.

19 Ikeda Y, Toda G, Hasimoto N, Kurokawa K. Antibody to superoxide dismutase, autoimmune hepatitis and antibody tests for hepatitis C virus. Lancet 1990; 335: 1345-6.

20 Theilmann L, Blazek M, Goeser T, et al. False-positive antiHCV tests in rheumatoid arthritis. Lancet $1990 ; 335: 1346$.

11 Bouchart D , Lucas J-C Muller J-Y, et al. False-positive hepatitis $\mathrm{C}$ virus antibody tests in paraproteinaemia. Lancet 1990; 336: 63.

22 Ellis LA, Brown D, Conradie JD, et al. Prevalence of Hepatitis $\mathrm{C}$ in South Africa: detection of anti-HCV in recent and C in South Africa: detection of anti-HCV

23 Lok ASF, Ma OCK, Chan T-M, et al. Overestimation of the prevalence of antibody to hepatitis $C$ virus in retrospective studies on stored sera. Hepatology 1991; 14: 756-62.

24 Khuroo MS, Dar MY, Zargar SA, et al. Hepatitis C virus antibodies in acute and chronic liver disease in India. F Hepatol 1993; 17: 175-9.

25 McHutchison JG, Person JL, Govindarajan S, et al. Improved detection of Hepatitis $\mathrm{C}$ virus antibodies in high-risk populations. Hepatology 1992; 15: 19-25.

26 Alberti A. Diagnosis of hepatitis C. Facts and perspectives. f Hepatol 1991; 12: 279-82.

27 Cassani $F$, Muratori L Manotti $P$, et al. Serum autoantibodies and the diagnosis of type-1 autoimmune hepatitis in Italy: a and the diagnosis of type-1 autoimmune hepatitis in Italy: a reappraisal in the

28 Lunel F, Abuaf N, Frangeuil L, et al. Liver/kidney microsome antibody type 1 and hepatitis $\mathrm{C}$ virus infection. Hepatology 1992; 16: 630-6.

29 Van der Poel CL, Cuypers HTM, Reesink HW, et al. Confirmation of hepatitis $C$ virus infection by new fourantigen recombinant immunoblot assay. Lancet 1991; 337 $317-9$.

30 Papo T, Marcellin P, Bernuau J, et al. Autoimmune chronic active hepatitis exacerbated by alpha interferon. Ann Intern Med 1992; 116: 51-3.

31 Shindo M, DiBisceglie AM, Hoofnagle JH. Acute exacerbation of liver disease during interferon alpha therapy for chronic hepatitis C. Gastroenterology 1992; 102: 1406-8. 